Research Article

\title{
Spinning Process Test and Optical Topography Measurement Technology for the Shell with Longitudinal and Latitudinal Inner Ribs
}

\author{
Wei Liang $\mathbb{D}^{1},{ }^{1}$ Qiongying $L v \mathbb{D}^{1},{ }^{1}$ Lin Guan $\mathbb{D}^{2},{ }^{2}$ and Zhigang Xing $\mathbb{D}^{1}$ \\ ${ }^{1}$ College of Mechanical and Electrical Engineering, Changchun University of Science and Technology, Changchun, \\ Jilin 130022, China \\ ${ }^{2}$ College of Foreign Languages, Changchun University of Science and Technology, Changchun, Jilin 130022, China
}

Correspondence should be addressed to Wei Liang; liang811@cust.edu.cn

Received 30 July 2019; Revised 13 November 2019; Accepted 19 November 2019; Published 18 December 2019

Academic Editor: Dimitrios E. Manolakos

Copyright (c) 2019 Wei Liang et al. This is an open access article distributed under the Creative Commons Attribution License, which permits unrestricted use, distribution, and reproduction in any medium, provided the original work is properly cited.

The paper studies the complicated problem in the spinning process of the shell with longitudinal and latitudinal inner ribs. The finite element software ABAQUS is used to establish the finite element model of the cylindrical shell with the longitudinal and latitudinal inner ribs. The numerical simulation of the spinning process is carried out. The stress distribution and strain distribution of the inner and outer surfaces during the spin-forming process are determined, and the orthogonal test method is used to determine the optimization process test parameters. The influence of the main process parameters on the wall thickness difference of the inner rib shell is obtained by the range analysis: wall thickness reduction rate $>$ rotary wheel feed speed $>$ rotor working angle (arranging according to their influences). And then the corresponding process parameters recommended by the spinning test are given. The measurement problem of inner ribs is solved by building of the robot shape measurement system which helps detect the three-dimensional shape of the inner ribs, and the precision of the spun sample was detected by the point cloud deviation comparison.

\section{Introduction}

Due to the limitations of equipment and processing capabilities, large-diameter and high-strength steel cylindrical parts, such as the launch vehicle engine casing, are often cast, welded, or milled domestically. Among them, the casting process was prone to blisters and loose structures with too large weight of the cast products; the welding process parts would generate excessive stress, and the chemical milling process causes too much pollution to meet the requirements of sustainable development $[1,2]$. With the continuous development of spinning technology, the method of obtaining cylindrical parts by spinning technology has been further applied in the fields of aerospace and military industry, especially for cylindrical parts with longitudinal ribs or latitudinal ribs. And the parts which are spun by the spinning process have the internal reinforcing ribs as the result of the spinning flow of the metal and do not generate excessive stress like the welding ribs. The blank does not damage the metal grains under the strong spin forming, and the metal fibers can be maintained. Its continuity and integrity improve the material and mechanical properties of the cylindrical part, making its performance much higher than that of the ribbed shell produced by milling, while achieving a high surface finish [3-6].

Although there are many advantages to use a spinning process to obtain a cylindrical parts with longitudinal ribs or latitudinal ribs, the forming process is also influenced by some spinning parameters, such as the thinning reduction rate, the spindle rotation speed, the gap between the rotary wheel and the mandrel, the feed amount, the lower amount, and the working angle of the rotating wheel $[7,8]$. There has not been report for the process of spinning with the longitudinal and circumferential stiffener at the same time. In order to obtain a qualified finished product with longitudinal and latitudinal inner ribs, it is necessary to bring all the 
influencing parameters into the spinning system for testing, obtain the best combination of parameters from a large number of tests, and follow up with the best parameters in processing. However, obtaining the spinning parameters through the test method not only causes waste of materials, but also wastes a lot of time, which puts pressure on the subsequent processing and manufacturing cycle. Besides, since many process parameters affect the forming quality which makes it difficult to obtain the optimum process parameters through a large number of process tests, it is unreasonable to obtain the best parameters by the blind process test method [9-13]. In this paper, based on the finite element software ABAQUS, the finite element model is established, and the machining process is numerically simulated. Through the numerical simulation and single-factor process test, the thinning rate and the forming of the rotor as well as the influence of the angle and feed rate on the roundness error and the wall thickness deviation are obtained. The rotation spinning of the shell with longitudinal and circumferential inner stiffener is completed. Later by constructing the robot topography measuring system, the sample underwent three-dimensional shape inspection and verification of its accuracy.

\section{Spinning Simulation and Test}

2.1. Spinning Principle. Spinning is a plastic working method that uses a rotating wheel to apply pressure to a blank to produce continuous local plastic deformation to obtain a desired hollow rotary part $[14,15]$. Spinning usually involves slab blanks or preformed blanks being clamped on the mandrel with the tail cap, rotating together under the driving of the main shaft, and the rotating wheel performs the feeding motion to produce continuous, point-by-point plastic deformation, so that the blank is in close contact with the core mold to produce the required variety of hollow rotor parts $[16,17]$. The processing principle is shown in Figure 1 and the simulation model is shown in Figure 2, where 1 is the mandrel, 2 is the spun workpiece, 3 is the rotating wheel, and 4 is the workblank.

\subsection{Simulation Modeling of Spinning Forming Process.} The spinning forming mechanism of the shell with longitudinal and latitudinal inner ribs is very complicated with many process parameters in consideration. Besides defining the weight of these parameters, adjusting the space and the amplitude is the key in the spinning process test. In order to carry out the scientific prediction of parameters and process optimization more effectively before spinning, it is necessary to have numerical simulation experiments with its technical support for the final process experiment [18-20]. In the simulation analysis, the CAD model of the mold and the tube blank is built in the SolidWorks system, and the CAD models of the mandrel, the rotary wheel, and the blank are, respectively, output in the IGS file format. Considering the time consumption of the numerical simulation, only the

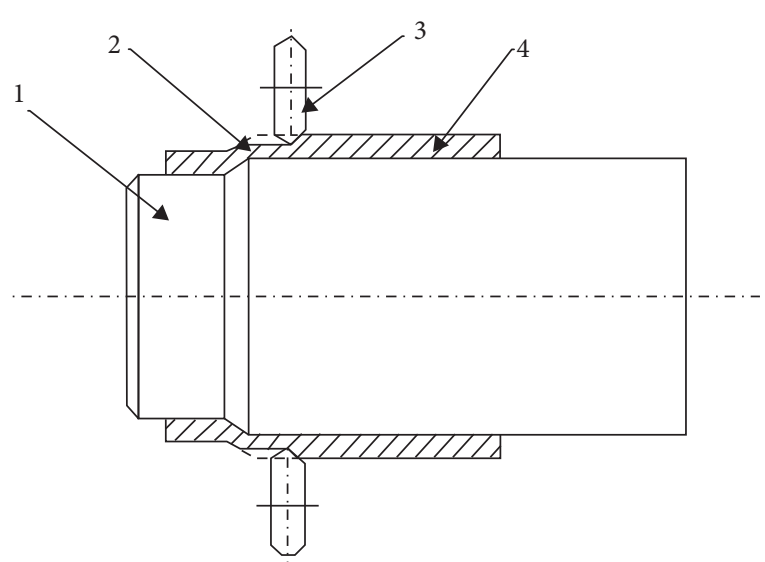

FIGURE 1: Spinning principle.

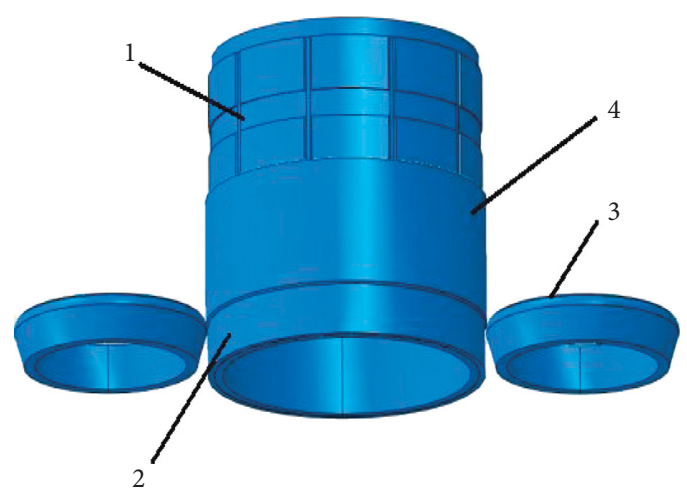

Figure 2: Simulation model.

mandrel and the working surface output of the rotating wheel are used to replace the solid model. The layout of the simulation model is shown in Figure 2. The blank is fixed on the mandrel in a positive rotation manner, and the two rotating wheels are $180^{\circ}$ symmetrically arranged. The detailed simulation modeling geometric parameters are shown in Table 1. The simulated blank is a cylindrical part with a circumferential spacer ring. The detailed properties of the material 5A06 (LF6) are shown in Table 2. The target workpiece size is shown in Figure 3.

In the spinning simulation, the rotating wheel and the mandrel are regarded as rigid bodies, and the rotating wheel is analytical rigid body without dividing the meshes. The mandrel is a discrete rigid body of R3D4 four-point three-dimensional bilinear rigid quadrilateral units. Since the fillet radius of the longitudinal and transverse ribs is very small, with the rib groove depth of $2.5 \mathrm{~mm}$, the mandrel units are divided as small as possible, a total of 388,087 units and 37,703 total nodes, so as to accurately simulate the material forming situation at the rib groove. The mandrel meshing is shown in Figure 4. The workblank is regarded as a deformed body and meshed by C3D8R eight-node linear hexahedral units with a total number of 34,000 and the total nodes is 45,800 , which is shown in Figure 5.

The spinning process is positive rotation, so the threeway displacement constraint of the spinning end is limited, 
TABLE 1: Geometric parameters of spinning simulation modeling.

\begin{tabular}{lcccc}
\hline $\begin{array}{l}\text { Rotary round } \\
\text { radius } r(\mathrm{~mm})\end{array}$ & $\begin{array}{c}\text { Rotary diameter } \\
D(\mathrm{~mm})\end{array}$ & $\begin{array}{c}\text { Rotary wheel working } \\
\text { angle } \alpha\left(^{\circ}\right)\end{array}$ & $\begin{array}{c}\text { Blank inner diameter } \\
D(\mathrm{~mm})\end{array}$ & $\begin{array}{c}\text { Blank outer diameter } \\
D(\mathrm{~mm})\end{array}$ \\
\hline 7 & 280 & 20 & 395 & 412 \\
\hline
\end{tabular}

TABLe 2: Material performance parameters.

\begin{tabular}{lcccc}
\hline Material density $\left(\mathrm{mg} / \mathrm{mm}^{3}\right)$ & Elastic modulus $(\mathrm{GPa})$ & Poisson's ratio & $K$ value & $N$ value \\
\hline 2.64 & 68.2 & 0.33 & 525.4 & 0.1956 \\
\hline
\end{tabular}

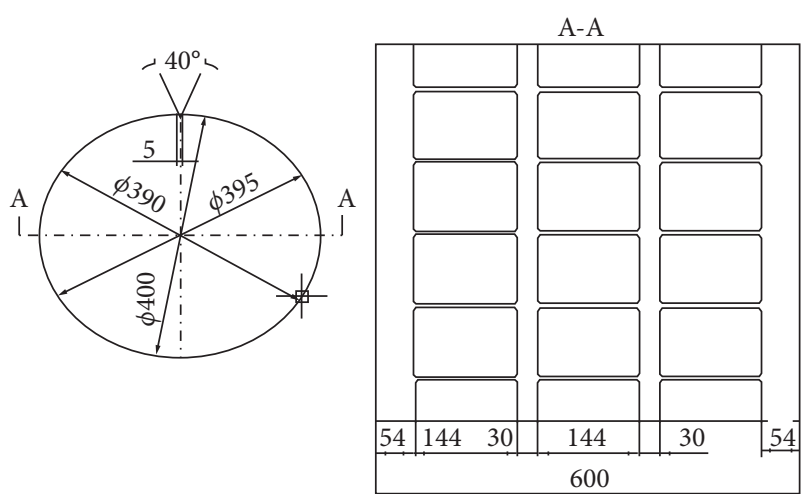

FIgURE 3: Target workpiece in spinning simulation.

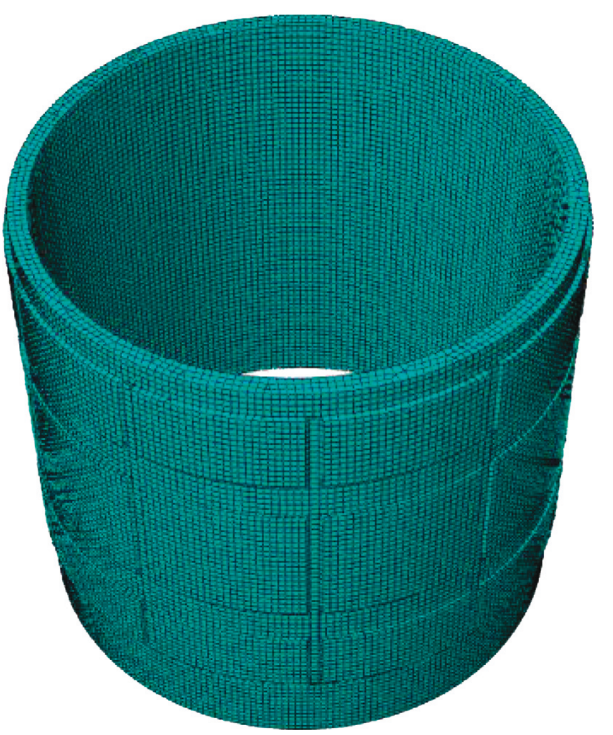

Figure 4: Mandrel meshing.

and the radial rotation of the blank is restricted to be consistent with the attitude of the mandrel. The displacement constraint is shown in Figure 6. The workblank is defined as a surface contact with the mandrel and the rotating wheel, and the contact relationship is Coulomb friction with a friction coefficient of 0.2. During the spinning simulation process, the motion of the two rotating wheels can be simplified as the space spiral motion of the rotary wheel around the workblank. The motion space trajectory is shown in Figure 7, and the corresponding motion equation is shown in the following equation:

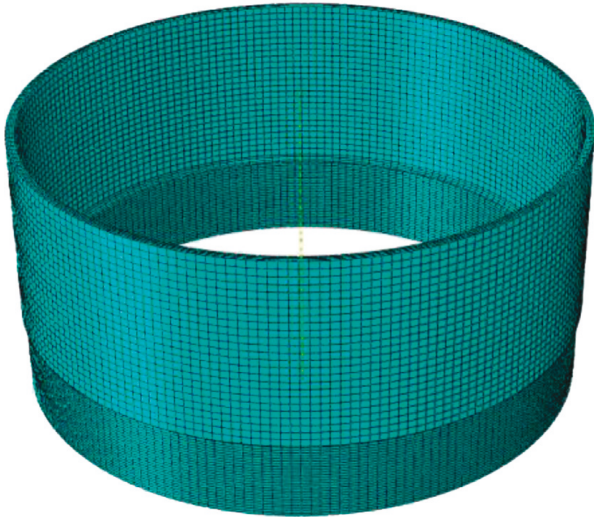

FIgURE 5: Blank meshing.

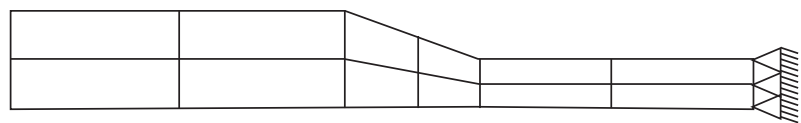

Figure 6: Three-way displacement constraint.

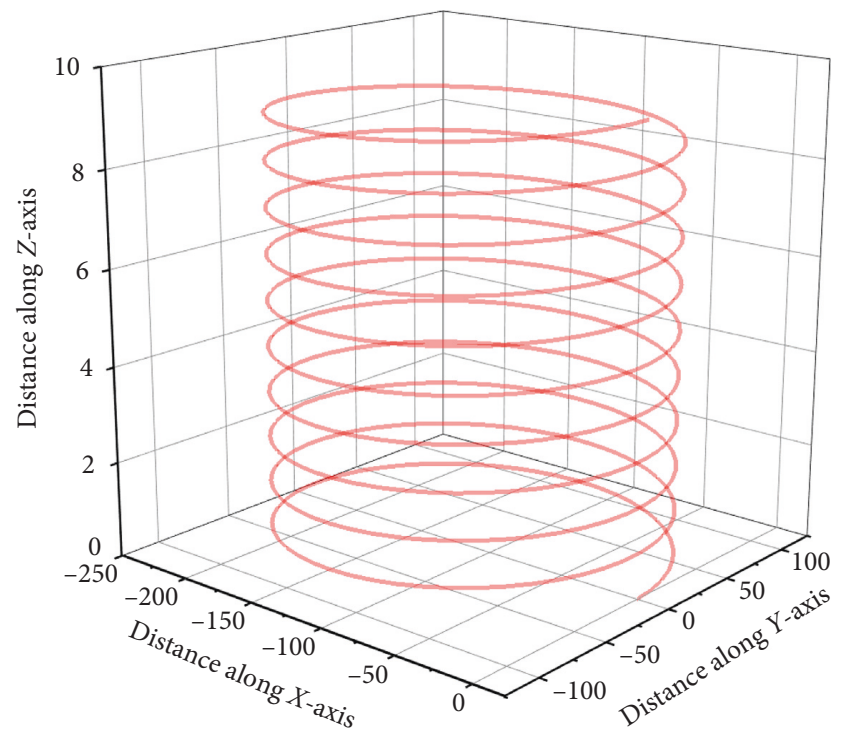

FIgURE 7: Spatial spiral motion.

$$
\left\{\begin{array}{l}
x=d \cos \theta-d, \\
y=d \sin \theta, \\
z=z .
\end{array}\right.
$$


In equation (1), $\theta$ is the angle of rotation of the rotary wheel, $d$ is the center distance between the blank and the rotary wheel, and $z$ is the axial feed distance of the rotary wheel [21-24]. The speed of the wheel is calculated from the spindle speed.

2.3. Orthogonal Test Design. Orthogonal test design can maximize the variation of optimization objectives caused by various factors and their interactions with a minimum number of trials [25]. Through the orthogonal test design, the influence of each process parameter level on the forming quality evaluation parameters can be analyzed, which is helpful to provide guidance for actual production [26, 27]; at the same time, the primary and secondary relationships of each process parameters which affect the quality of the workpiece in spinning can be analyzed, which is convenient for the process parameter control.

For the longitudinal and latitudinal inner rib shell, the three test factors mainly affecting the forming quality are selected: the working angle, the thinning rate, and the feed speed of the rotating wheel. If 5 levels are selected for each test factor, according to the basic properties of the orthogonal test table $L_{25}\left(3^{5}\right)$, the factors and levels are shown in Table 3.

There are 25 kinds of simulation test combinations established by this method, as shown in Table 4. The Mises stress diagram and equivalent strain diagram of the typical longitudinal and latitudinal inner ribs forming are shown in Figures 8-13.

The process parameters of the cloud diagrams of Figures 8 and 9 are as follows: the rotary wheel angle $\alpha=17^{\circ}$, the thinning rate $\Psi=43 \%$, and the feed rate $f=120 \mathrm{~mm} / \mathrm{min}$. It can be seen that the rib-forming material is not filled and the strain at the upper part of the ribs is not complete, especially the forming effect of the ring rib is not good, and the metal filling forming is insufficient. It is preliminarily presumed that the rotary wheel angle is relatively small due to the small stress value (the upper part of the ribs is green), and the thinning rate in this process parameter is relatively small due to the insufficient metal filling in the inner ribs.

The process parameters of the cloud diagrams of Figures 10 and 11 are as follows: the rotary wheel angle $\alpha=20^{\circ}$, the thinning rate $\Psi=46 \%$, and the feed rate $f=150 \mathrm{~mm} / \mathrm{min}$. It can be seen that the filling degree of the longitudinal and latitudinal inner ribs is better than that of the thinning rate $\Psi=43 \%$, the strain at the upper part of the ribs is not complete, the forming effect of the latitudinal ribs is acceptable, and the metal filling forming is relatively perfect. It is preliminarily presumed that the rotary wheel angle is moderate, but certain stress concentration can be seen in the strain cloud diagram of latitudinal ribs. It is considered that the feed speed can be adjusted to adjust this phenomenon.

The process parameters of the cloud diagrams of Figures 12 and 13 are as follows: the rotary wheel angle $\alpha=22^{\circ}$, the thinning rate $\Psi=50 \%$, and the feed rate $f=180 \mathrm{~mm} / \mathrm{min}$. It can be seen from the stress cloud diagram that the longitudinal and latitudinal inner ribs are sufficiently filled with a thorough pressure of the upper part of the ribs. But the
TABLE 3: Factors and levels in the orthogonal test.

\begin{tabular}{lccc}
\hline Factors and levels & $\begin{array}{c}\text { A-rotary wheel } \\
\text { angle } \alpha\left(^{\circ}\right)\end{array}$ & $\begin{array}{c}\text { B-thinning } \\
\text { rate } \Psi(\%)\end{array}$ & $\begin{array}{c}\text { C-feed rate } f \\
(\mathrm{~mm} / \mathrm{min})\end{array}$ \\
\hline 1 & 15 & 40 & 100 \\
2 & 17 & 43 & 120 \\
3 & 20 & 46 & 150 \\
4 & 22 & 50 & 180 \\
5 & 25 & 53 & 220 \\
\hline
\end{tabular}

TABle 4: Orthogonal test results.

\begin{tabular}{|c|c|c|c|c|}
\hline \multirow[b]{2}{*}{$\begin{array}{l}\text { Test } \\
\text { number }\end{array}$} & \multicolumn{3}{|c|}{ Process parameters } & \multirow{2}{*}{$\begin{array}{c}\text { Simulation } \\
\text { result } \\
\text { Wall thickness } \\
\text { difference } L \\
(\mathrm{~mm})\end{array}$} \\
\hline & $\begin{array}{c}\text { Rotary wheel } \\
\text { working angle } \\
\alpha\left(^{\circ}\right)\end{array}$ & $\begin{array}{c}\text { Thinning } \\
\text { rate } \Psi \\
(\%)\end{array}$ & $\begin{array}{c}\text { Feed speed } \\
f(\mathrm{~mm} / \\
\mathrm{min})\end{array}$ & \\
\hline 1 & 1 & 1 & 1 & 0.135 \\
\hline 2 & 1 & 2 & 2 & 0.128 \\
\hline 3 & 1 & 3 & 3 & 0.144 \\
\hline 4 & 1 & 4 & 4 & 0.156 \\
\hline 5 & 1 & 5 & 5 & 0.135 \\
\hline 6 & 2 & 1 & 2 & 0.155 \\
\hline 7 & 2 & 2 & 3 & 0.124 \\
\hline 8 & 2 & 3 & 4 & 0.131 \\
\hline 9 & 2 & 4 & 5 & 0.105 \\
\hline 10 & 2 & 5 & 1 & 0.089 \\
\hline 11 & 3 & 1 & 3 & 0.148 \\
\hline 12 & 3 & 2 & 4 & 0.152 \\
\hline 13 & 3 & 3 & 5 & 0.118 \\
\hline 14 & 3 & 4 & 1 & 0.124 \\
\hline 15 & 3 & 5 & 2 & 0.159 \\
\hline 16 & 4 & 1 & 4 & 0.144 \\
\hline 17 & 4 & 2 & 5 & 0.153 \\
\hline 18 & 4 & 3 & 1 & 0.125 \\
\hline 19 & 4 & 4 & 2 & 0.123 \\
\hline 20 & 4 & 5 & 3 & 0.168 \\
\hline 21 & 5 & 1 & 5 & 0.092 \\
\hline 22 & 5 & 2 & 1 & 0.177 \\
\hline 23 & 5 & 3 & 2 & 0.136 \\
\hline 24 & 5 & 4 & 3 & 0.165 \\
\hline 25 & 5 & 5 & 4 & 0.113 \\
\hline
\end{tabular}

forming effect of the latitudinal ribs is not good, and the stress is too large and concentrated. It is preliminarily presumed that this situation is caused by the excessive rotary wheel angle and feed speed.

The above enumerates the simulation effects of several sets of simulation parameter combinations with brief analyses. Because there is such a large amount of data in the simulation, the 25 process combinations will not be listed one by one. In order to find a suitable set of parameters, we evaluate the wall thickness difference in the simulation data for the orthogonal target analysis and then give the appropriate combination of parameters recommended for use in the spinning test. Figure 14 is one of the simulation forming models of the longitudinal and latitudinal inner ribs.

\subsection{Simulation Result Analysis}

2.4.1. Analysis of Orthogonal Test Results. According to the sorting of the orthogonal test table, the wall thickness 


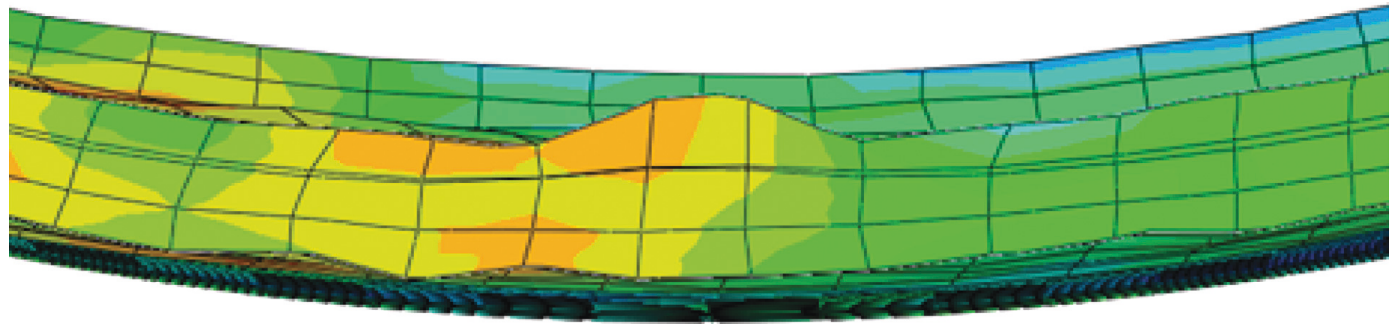

S, Mises

(Avg: $75 \%$ )

$+1.250 e+02$

$+1.250 e+02$
$+1.154 e+02$

$+1.154 e+02$
$+1.058 e+02$

$+9.617 e+01$

$+8.695 e+01$

$+7.695 e+01$

$+6.735 e+01$

$+6.735 e+01$
$+5.774 e+01$

$+4.813 e+01$

$+3.852 e+01$

$+2.891 e+01$

$+1.930 e+01$

$+9.695 e+00$

PEEQ

(Avg: $75 \%$ )

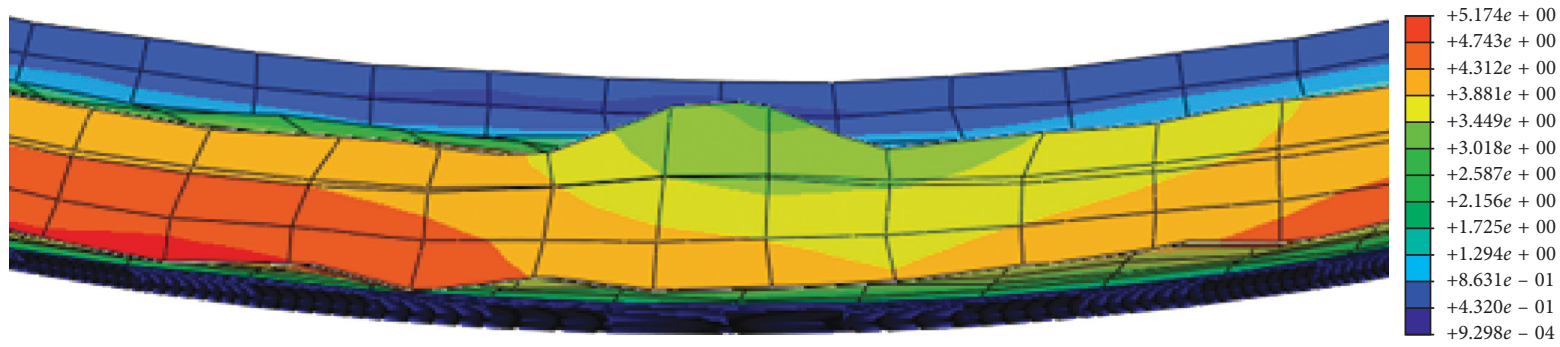

FIGURE 8: Mises stress diagram and equivalent strain diagram of the longitudinal ribs $\left(\alpha=17^{\circ}, \Psi=43 \%\right.$, and $\left.f=120 \mathrm{~mm} / \mathrm{min}\right)$.

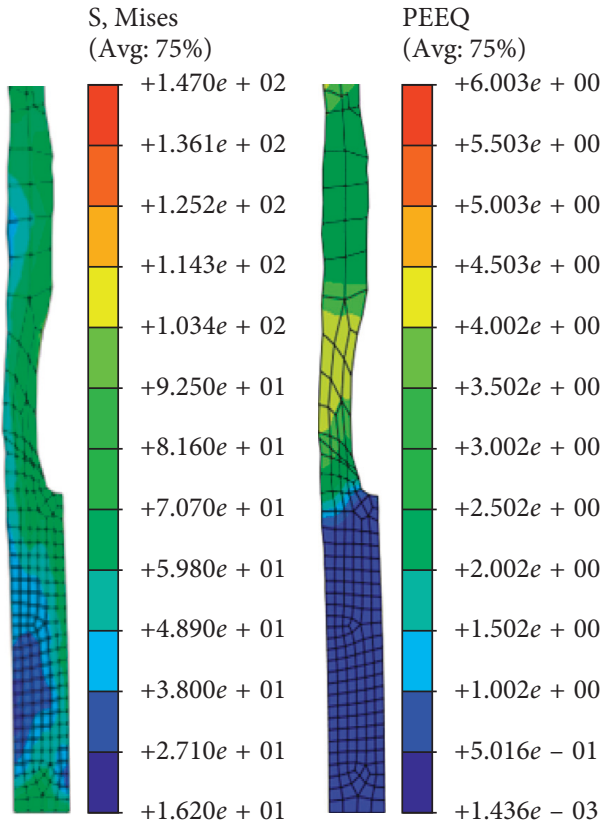

FIGURE 9: Mises stress diagram and equivalent strain diagram of the latitudinal ribs $\left(\alpha=17^{\circ}, \Psi=43 \%\right.$, and $\left.f=120 \mathrm{~mm} / \mathrm{min}\right)$.

difference is taken into consideration, and the ABAQUS numerical simulation result is analyzed in the orthogonal test. Table 4 shows the results of the orthogonal test, and the results of the range analysis of the orthogonal test are shown in Table 5.

In order to describe the influence of the process parameters of the outer latitudinal spinning on the wall thickness difference more intuitively and clearly, the "trend chart" is used to illustrate the influence trend of the variation of each factor level on the wall thickness difference index. The four factors of each process parameter represented by 1 ,
$2,3,4$, and 5 are shown in Table 3 . The trend chart of the wall thickness difference of shell parts with the longitudinal and latitudinal inner ribs is shown in Figure 15.

Through the range analysis of Table 5 , it can be concluded that the main process parameters have a significant influence on the wall thickness difference of the inner rib shell: the wall thickness reduction rate $\Psi(R=0.0268)>$ the rotation speed of the rotary wheel $f(R=0.0198)>$ rotary wheel working angle $\alpha(R=0.0268)$. The optimum process data are obtained by analyzing the best combination of the trend group with the minimum wall thickness difference as the optimization target in Figure 15 as A3, B4, and C3, corresponding to the data in Table 1 . The optimal process data parameters of the orthogonal test are shown in Table 6.

2.5. Spinning Forming Process Test. According to the size and shape characteristics and technical requirements of shell parts with longitudinal and latitudinal inner ribs, two samples with a diameter of $1: 2$ are used for process test. In accordance with the results of finite element simulation and analysis, the shell parts with inner rib of $2.5 \mathrm{~mm}$ and $4 \mathrm{~mm}$ in height are spun, respectively. Table 7 shows the parameters of the sample with $2.5 \mathrm{~mm}$ height ribs, and Table 8 shows the parameters of the sample with $4 \mathrm{~mm}$ height ribs.

The experimental equipment used is QX62-250 twowheel powerful spinning machine. The main technical parameters of the equipment are shown in Table 9.

The process test process is divided into two steps. First is the forming test of the workpiece with $2.5 \mathrm{~mm}$ rib height and then with $4 \mathrm{~mm}$ rib height. According to the calculation, the blank size of the sample with $2.5 \mathrm{~mm}$ rib height is as follows: the inner diameter of the workblank (the inner diameter of the skin) is $395 \mathrm{~mm}$, the outer diameter is determined as $412 \mathrm{~mm}$ according to the thinning rate, and the workblank length is $390 \mathrm{~mm}$. The workblank size of the sample with 


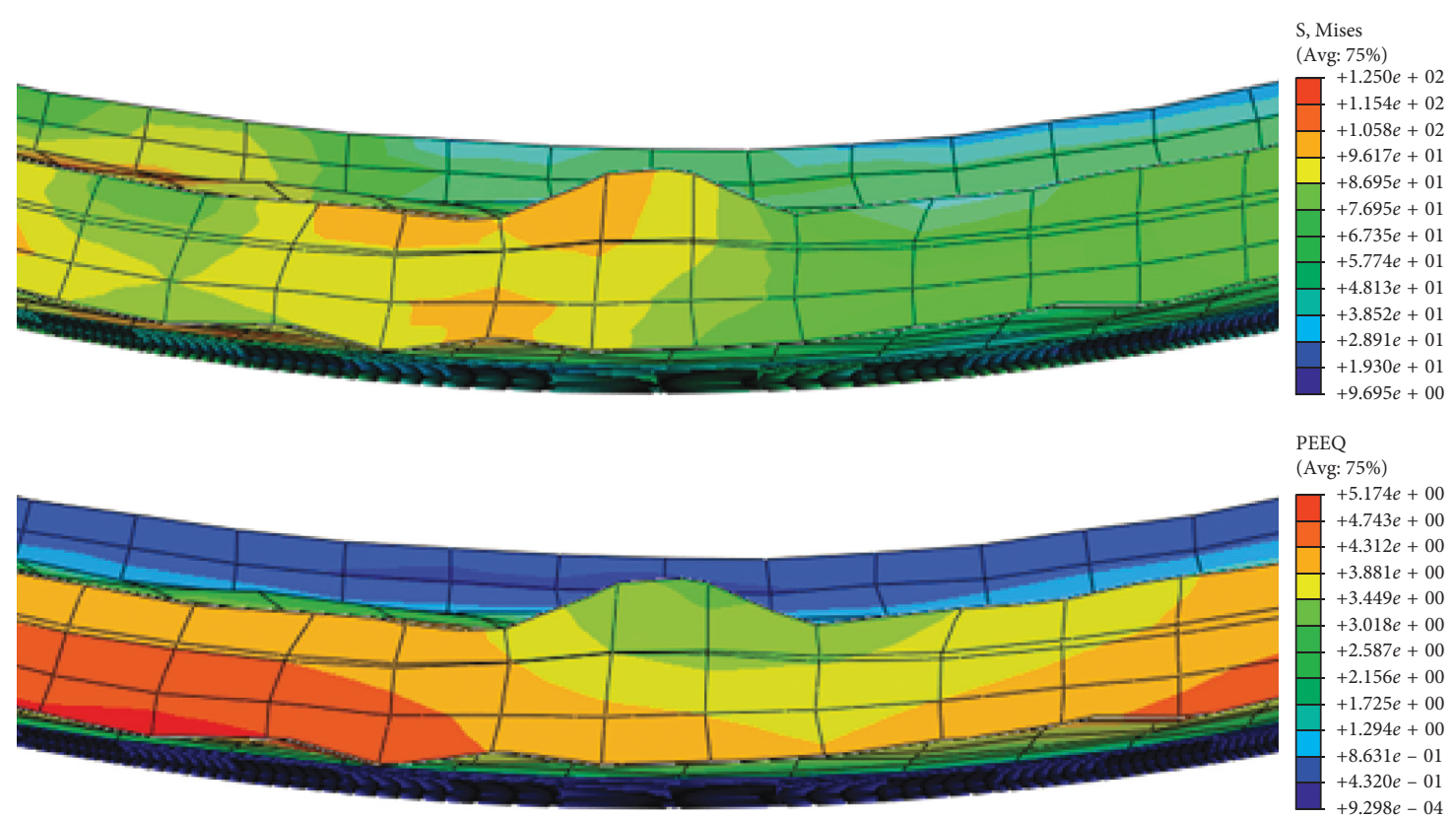

Figure 10: Mises stress diagram and equivalent strain diagram of the longitudinal ribs $\left(\alpha=20^{\circ}, \Psi=46 \%\right.$, and $\left.f=150 \mathrm{~mm} / \mathrm{min}\right)$.

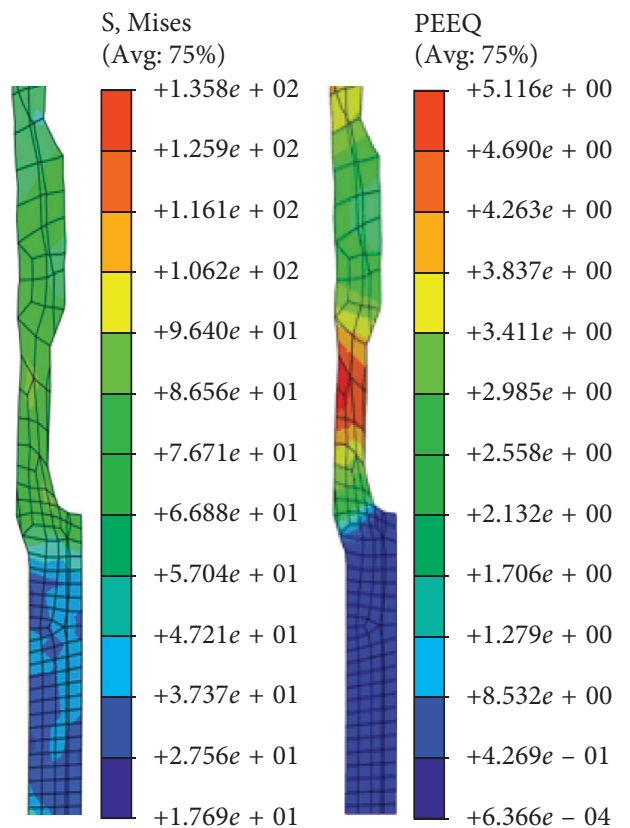

FIGURE 11: Mises stress diagram and equivalent strain diagram of the latitudinal ribs $\left(\alpha=20^{\circ}, \Psi=46 \%\right.$, and $\left.f=150 \mathrm{~mm} / \mathrm{min}\right)$.

$4 \mathrm{~mm}$ rib height is as follows: the inner diameter of the blank is $395 \mathrm{~mm}$, the outer diameter is $420 \mathrm{~mm}$, and the workblank length is $440 \mathrm{~mm}$, as shown in Figure 16.

Because the shell parts have longitudinal and latitudinal inner ribs inside which lead to difficulties in unloading after spinning, the split mandrel can be designed and processed during the process test in order to solve the problem. The photo of the mandrel body is shown in Figure 17(a). The assembled state of the split mandrel is shown in Figure 17(b). The installation state of the blank, the split mandrel, and the rotary wheel before the spinning test is shown in Figure 17(c).

In the test of height $2.5 \mathrm{~mm}$ workpiece, spinning is carried out at room temperature. According to the analysis of the process test results, it is found that the feeding ratio of the part in Figure 18(a) is small, and the ribs are not easy to be filled; at the same time, although the thinning rate of the reinforcement is less than that of the skin when spinning at room temperature, the overall deformation is large and it is easy to crack under the action of axial tension due to the reduction and supplement of surrounding materials. In Figure 18(b), the feeding ratio of the piece is increased, but the problem of large overall deformation of the reinforcement part still exists, and there are still longitudinal cracks in the piece.

The results can reflect the influence of the feed rate on the spinning quality, that is, the increase of feed rate leads to the increase of rib height and the easy filling of metal in ribs, which is consistent with the results of simulation. The spinning effect is better when the feed rate is increased, while the spinning pressure will increase at the same time. So it must be considered comprehensively. Figures 19(a) and 19(b) are changed to offset spinning with offset values of $2.5 \mathrm{~mm}$ and $3.5 \mathrm{~mm}$, respectively. The effect is not ideal as the fracture phenomenon occurs in the longitudinal reinforcement part. Therefore, offset spinning is similar to two-pass spinning, which is not suitable for the forming of these kinds of parts.

In order to verify the influence of the rotary wheel corner radius on the forming quality, Figure 20(a) shows the rotary wheel corner radius $R=8 \mathrm{~mm}$ in the workpiece, and Figure 20(b) shows the rotary wheel corner radius $R=10 \mathrm{~mm}$ after a change. When the corner radius increases, the overlapping part of the track of the rotary wheel can be increased, thus improving the surface quality of the 


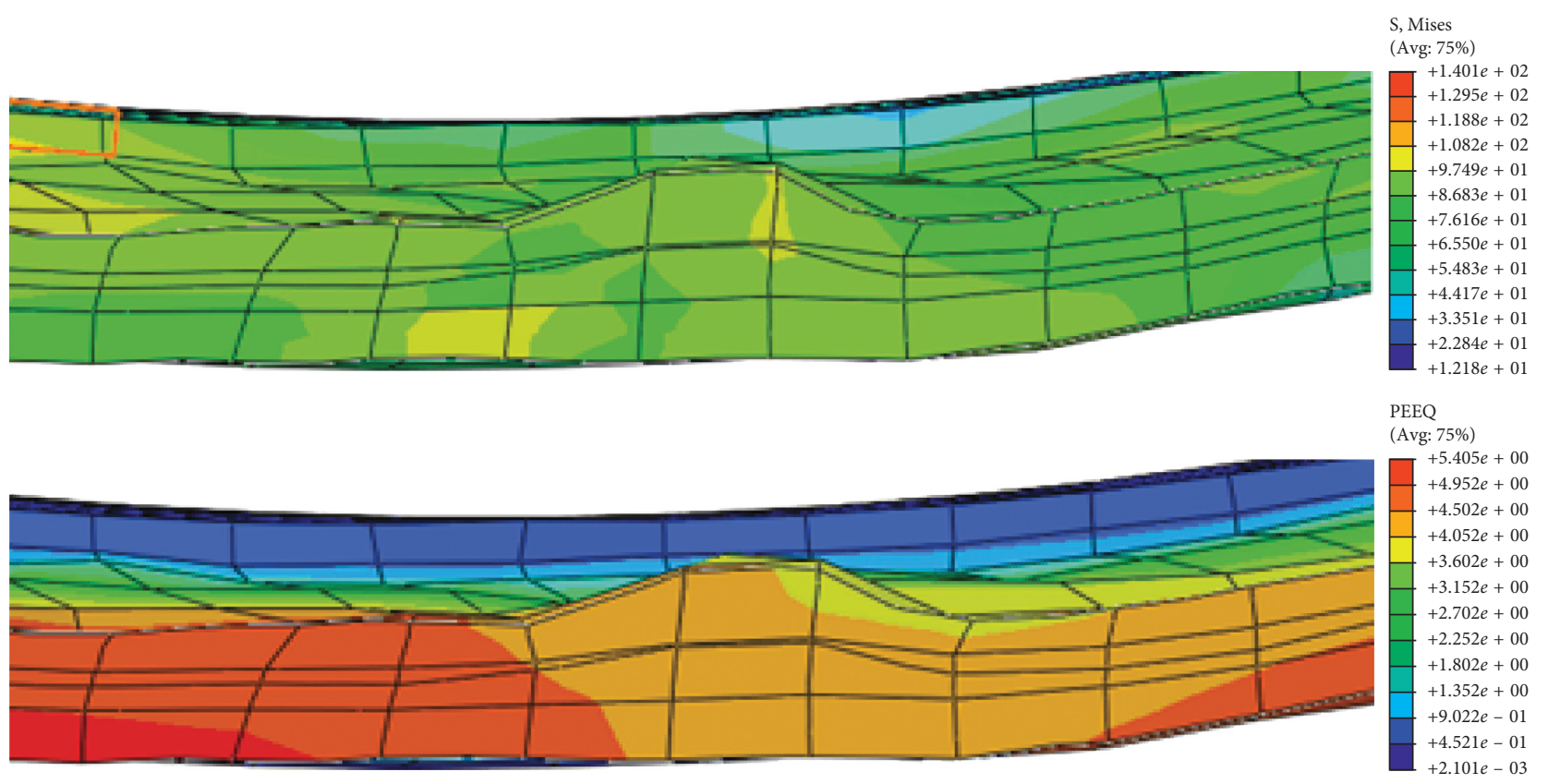

Figure 12: Mises stress diagram and equivalent strain diagram of the longitudinal ribs $\left(\alpha=22^{\circ}, \Psi=50 \%\right.$, and $\left.f=180 \mathrm{~mm} / \mathrm{min}\right)$.

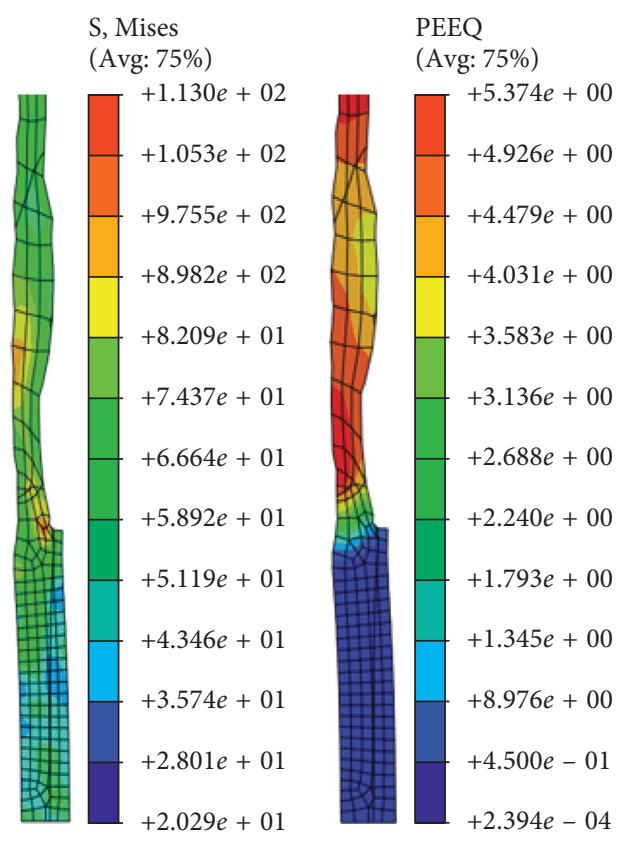

FIGURE 13: Mises stress diagram and equivalent strain diagram of the latitudinal ribs $\left(\alpha=22^{\circ}, \Psi=50 \%\right.$, and $\left.f=180 \mathrm{~mm} / \mathrm{min}\right)$.

workpiece, but at the same time, the spinning pressure increases. On the contrary, if the corner radius decreases, the spinning pressure becomes smaller, and the workpiece is easy to stick to the mold and affect the spinning quality. As a result, the final test $R=10 \mathrm{~mm}$ is the most suitable for forming with the best quality of the processing external surface.

Combined with the process parameters recommended by simulation, the relevant process parameters are verified by spinning forming test of short workblank, and the

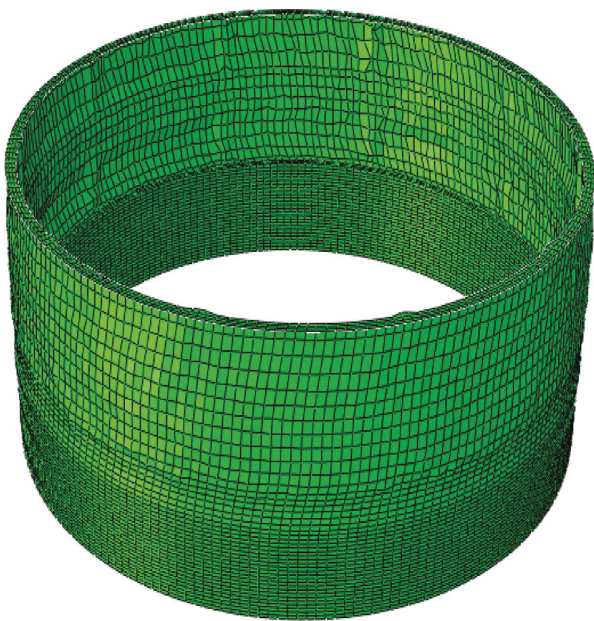

FIGURE 14: Forming model of ribs.

spinning process parameters that can be used in the practical test are given, shown in Table 10. Through the spinning test of the sample with long workblank, $2.5 \mathrm{~mm}$ inner rib height was finished, but there is a reduction of metal plastic fluidity in the process of spinning sample of $4 \mathrm{~mm}$ inner rib height. Thus, the preheating method of workblank can be considered to improve the plastic deformation ability of the material.

\section{Precision Control and Optical Measurement}

3.1. Precision Control. Because of the problem of circumferential deformation during the spinning process of the material with the longitudinal and latitudinal inner rib shell parts, the circumferential direction and the axial flow velocity of the material should be appropriate as well as the 
TABLe 5: Wall thickness difference analysis results.

\begin{tabular}{lccc}
\hline Test index & & $\begin{array}{c}\text { Wall thickness difference analysis } \\
\text { Thinning rate } \Psi(\%)\end{array}$ & Feed rate $f(\mathrm{~mm} / \mathrm{min})$ \\
\hline$K_{1}$ & 0.698 & 0.674 & 0.749 \\
$K_{2}$ & 0.701 & 0.734 & 0.701 \\
$K_{3}$ & 0.654 & 0.604 & 0.65 \\
$K_{4}$ & 0.713 & 0.673 & 0.696 \\
$K_{5}$ & 0.683 & 0.664 & 0.653 \\
$k_{1}$ & 0.1396 & 0.1348 & 0.1498 \\
$k_{2}$ & 0.1402 & 0.1468 & 0.1402 \\
$k_{3}$ & 0.1308 & 0.1308 & 0.13 \\
$k_{4}$ & 0.1426 & 0.1208 & 0.1392 \\
$R$ & 0.1366 & 0.1328 & 0.1306 \\
\hline
\end{tabular}

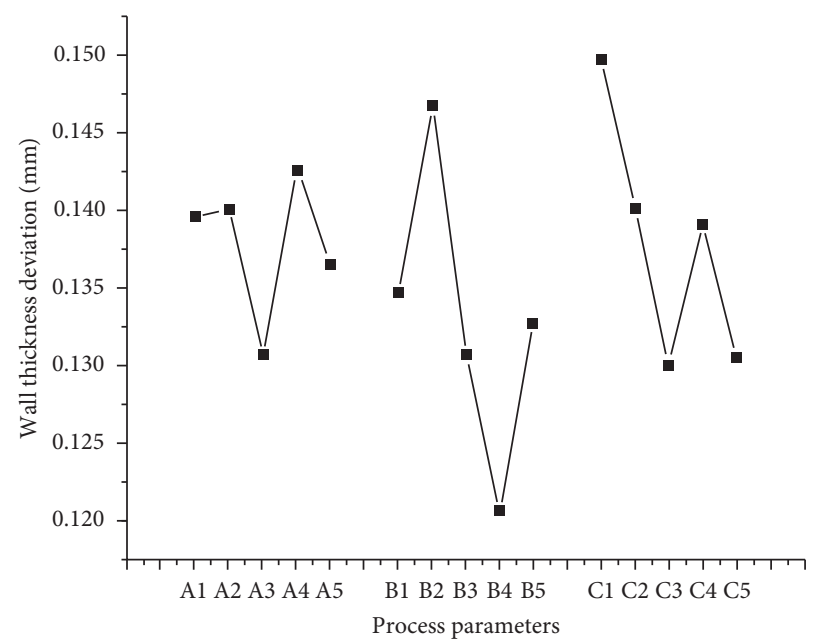

Figure 15: Wall thickness difference trend chart. A: rotary wheel working angle $\alpha\left(^{\circ}\right)$; B: thinning rate $\Psi(\%)$; : feed rate $f(\mathrm{~mm} / \mathrm{min})$.

TABLE 6: Orthogonal test recommended process parameters.

\begin{tabular}{lcc}
\hline Thinning rate $\Psi(\%)$ & Feed rate $f(\mathrm{~mm} / \mathrm{min})$ & Rotary wheel working angle $\alpha\left(^{\circ}\right)$ \\
\hline 50 & 150 & 20 \\
\hline
\end{tabular}

TABLE 7: Parameters of the sample with $2.5 \mathrm{~mm}$ height ribs.

\begin{tabular}{lccccccc}
\hline $\begin{array}{l}\text { Rib } \\
\text { height } \\
(\mathrm{mm})\end{array}$ & $\begin{array}{c}\text { Outer } \\
\text { diameter } \\
(\mathrm{mm})\end{array}$ & $\begin{array}{c}\text { Inside } \\
\text { diameter } \\
(\mathrm{mm})\end{array}$ & $\begin{array}{c}\text { Width of middle } \\
\text { latitudinal ribs } \\
(\mathrm{mm})\end{array}$ & $\begin{array}{c}\text { Width of end } \\
\text { latitudinal ribs } \\
(\mathrm{mm})\end{array}$ & $\begin{array}{c}\text { Numbers of } \\
\text { longitudinal } \\
\text { ribs }\end{array}$ & $\begin{array}{c}\text { Width of } \\
\text { longitudinal ribs } \\
(\mathrm{mm})\end{array}$ & $\begin{array}{c}\text { Gap between two } \\
\text { latitudinal ribs }(\mathrm{mm})\end{array}$ \\
\hline 2.5 & 405 & 395 & 30 & 50 & 10 & 6 & 144 \\
\hline
\end{tabular}

TABle 8: Parameters of the sample with $4 \mathrm{~mm}$ height ribs.

\begin{tabular}{lccccccc}
\hline $\begin{array}{l}\text { Rib } \\
\text { height } \\
(\mathrm{mm})\end{array}$ & $\begin{array}{c}\text { Outer } \\
\text { diameter } \\
(\mathrm{mm})\end{array}$ & $\begin{array}{c}\text { Inside } \\
\text { diameter } \\
(\mathrm{mm})\end{array}$ & $\begin{array}{c}\text { Width of middle } \\
\text { latitudinal ribs } \\
(\mathrm{mm})\end{array}$ & $\begin{array}{c}\text { Width of end } \\
\text { latitudinal ribs } \\
(\mathrm{mm})\end{array}$ & $\begin{array}{c}\text { Numbers of } \\
\text { longitudinal } \\
\text { ribs }\end{array}$ & $\begin{array}{c}\text { Width of } \\
\text { longitudinal ribs } \\
(\mathrm{mm})\end{array}$ & $\begin{array}{c}\text { Gap between two } \\
\text { latitudinal ribs }(\mathrm{mm})\end{array}$ \\
\hline 4 & 408 & 395 & 30 & 50 & 10 & 6 & 144 \\
\hline
\end{tabular}

TABle 9: Technical parameters of the spinning machine.

\begin{tabular}{lcccc}
\hline $\begin{array}{l}\text { Lateral spinning pressure } \\
(\mathrm{KN})\end{array}$ & $\begin{array}{c}\text { Longitudinal spinning pressure } \\
(\mathrm{KN})\end{array}$ & $\begin{array}{c}\text { Lateral distance } \\
(\mathrm{mm})\end{array}$ & $\begin{array}{c}\text { Longitudinal distance } \\
(\mathrm{mm})\end{array}$ & $\begin{array}{c}\text { Center height } \\
(\mathrm{mm})\end{array}$ \\
\hline 200 & 250 & 260 & 2200 & 600 \\
\hline
\end{tabular}




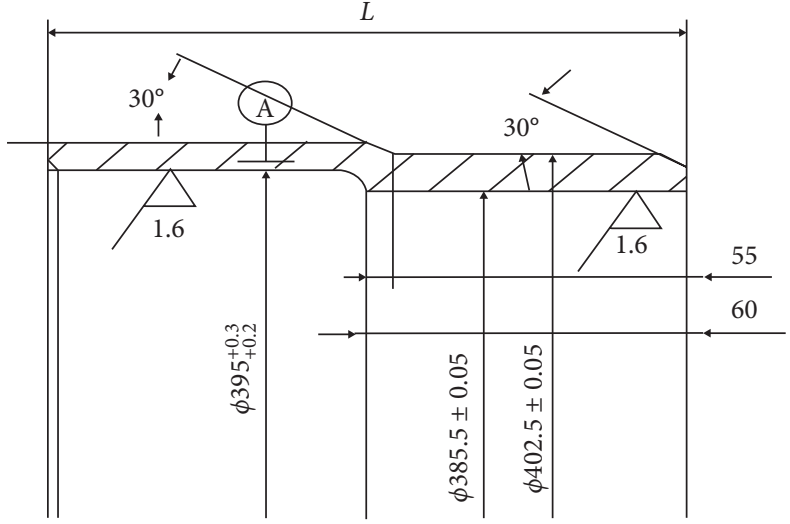

(a)

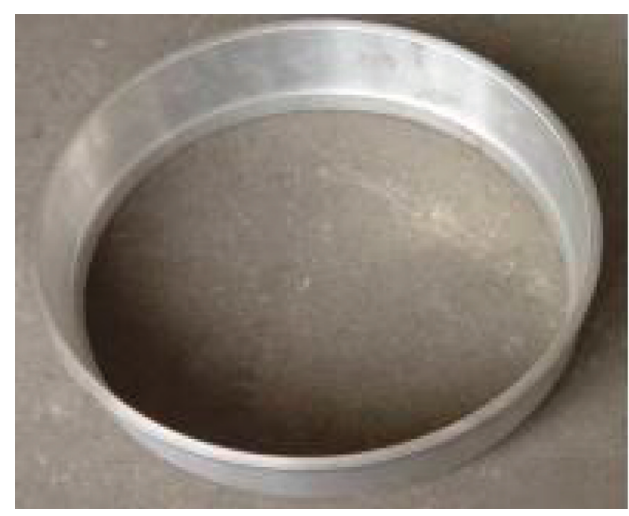

(b)

FIGURE 16: (a) Workblank drawings and (b) the workblank.

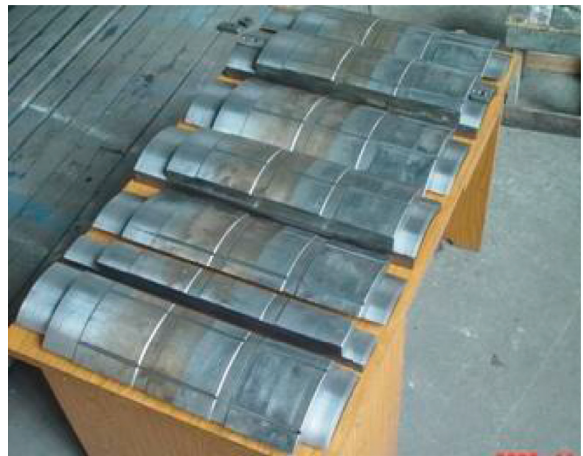

(a)

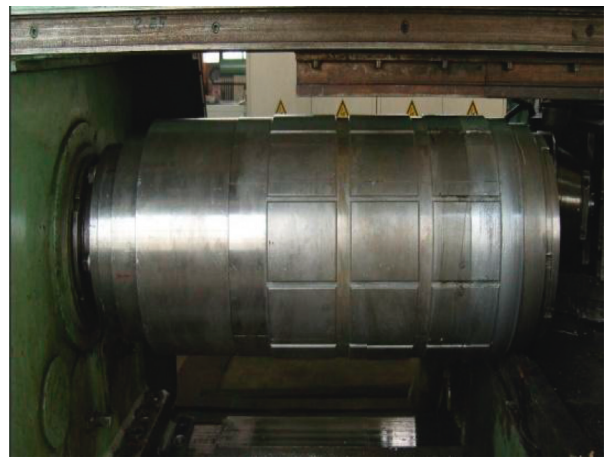

(b)

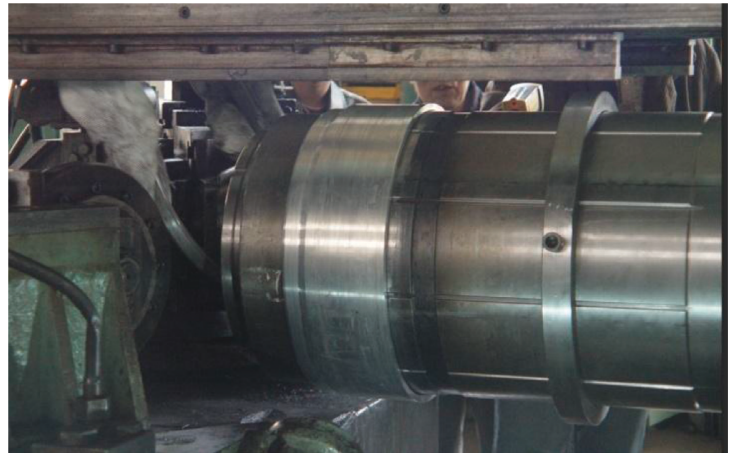

(c)

Figure 17: (a) Split state, (b) assembled state, and (c) installation state of the mandrel.

process parameters such as the feed rate, the spindle speed, and the thinning reduction during the actual machining process, which will affect the molding precision of the material. Besides, a part of the material is filled into the mandrel groove during the processing, which is uncontrollable without any limitation of the mandrel surface, and thus the flow of the material also directly affects the accuracy of the workpiece [28-30].

During the spinning process, the spinning wheel not only has a calendering effect on the metal material being spun and also has a leveling effect. Therefore, the spinning of conventional cylindrical parts can achieve the surface smoothness and dimensional accuracy, which is similar to mechanical processing [30-32]. During the spinning process, the forming of the ribs brings a series of negative effects, such as the depressions, cracks, or even breaks on the outer surface of the part, which are fatal to the surface finish and precision accuracy. The control of precision is to prevent all these defects.

Through the process test, the external surface depression of the part has a direct relationship with the skin thickness of the part. The thinner the skin thickness of the part is, the more likely the problem occurs. This is because the forming of the ribs leads to the reduction of the diameter and the total 


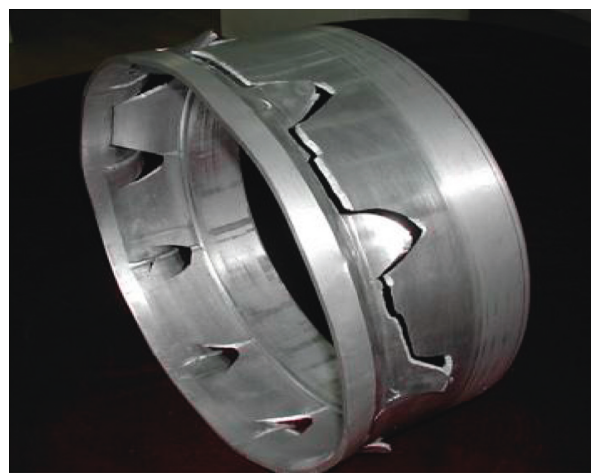

(a)

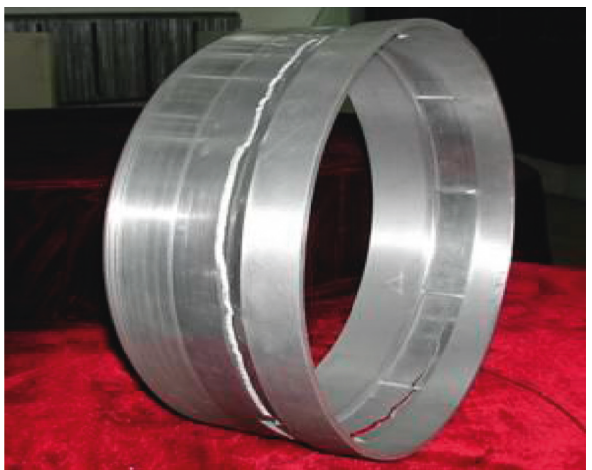

(b)

FIGURE 18: Cracking phenomenon. (a) Small feed ratio spinning sample and (b) large feed ratio spinning sample.

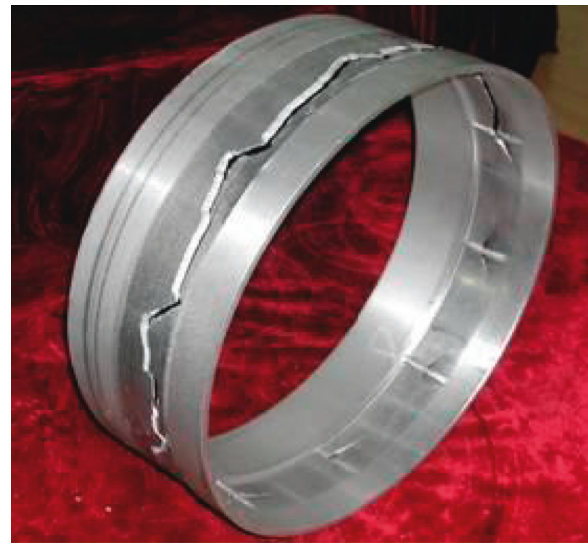

(a)

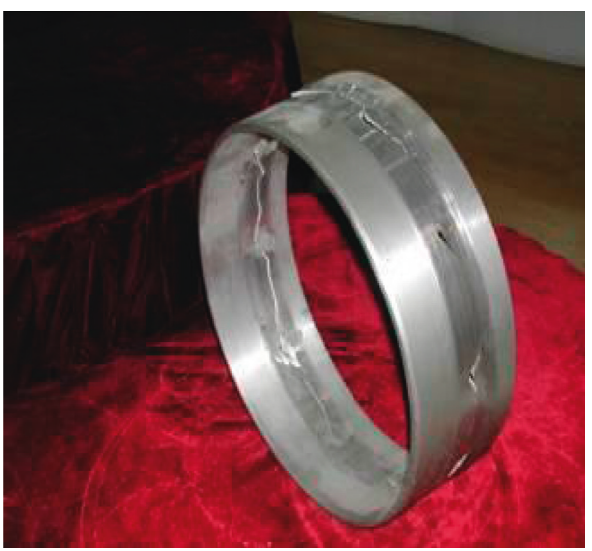

(b)

Figure 19: Crack phenomenon in offset spinning. (a) Sample with an offset value of $2.5 \mathrm{~mm}$ and (b) sample with an offset value of $3.5 \mathrm{~mm}$.

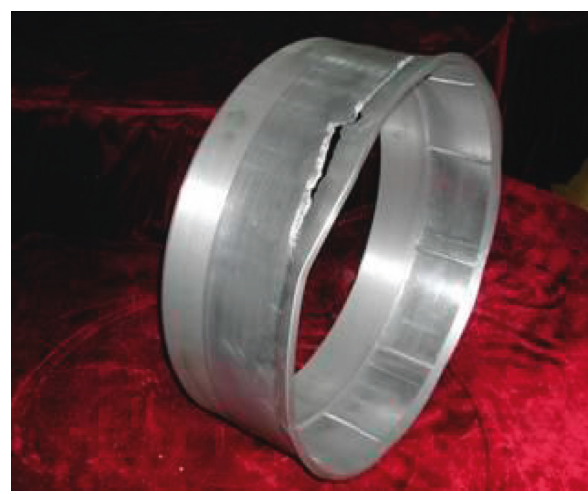

(a)

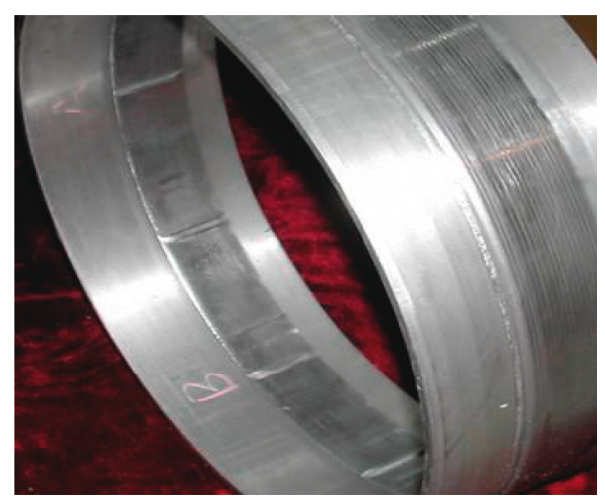

(b)

FIGURE 20: Cracks caused by inappropriate rotary wheel corner radius. (a) Corner radius of $8 \mathrm{~mm}$ and (b) corner radius of $10 \mathrm{~mm}$.

TABLE 10: Verified spinning process parameters.

\begin{tabular}{lccc}
\hline Thinning rate $\Psi(\%)$ & Feed rate $f(\mathrm{~mm} / \mathrm{min})$ & Rotary wheel working angle $\alpha\left({ }^{\circ}\right)$ & Rotary wheel corner radius $R(\mathrm{~mm})$ \\
\hline 50 & 150 & 20 & 10 \\
\hline
\end{tabular}


deformation. In addition, the formation of the longitudinal ribs causes the circumferential movement of the material, which easily results in the depressions on the outer surface of the ribs if the material is not replenished in time. On the contrary, as the skin thickness of the part increases, the corresponding blank thickness increases, and the material replenishment at the stiffeners during the spinning will be timely, and since the deformation of the ribs and the skin is close, there will be no or scarce external surface depression.

The parameters are optimized on the bases of the previous scaled sample experiments. Among them, the major process parameters such as the rotary wheel working angle, the thinning rate, and the feed rate are determined; the wall thickness of the workblank material and the fixing method of the mandrel are finely adjusted. Besides, the raw material is heated to $200^{\circ} \mathrm{C} \pm 20^{\circ} \mathrm{C}$ before spinning, and the propane heating gun is used for supplementary heating during the heating process. Through the above method, a sample piece of shell with rib height of $4.0 \mathrm{~mm}$ is finished, as is shown in Figure 21.

3.2. Optical Measurement. The main parameters of shape dimension measurement of parts with longitudinal and latitudinal inner ribs are inner diameter, outer diameter, thickness, rib height, etc. There is a precision requirement for the inner diameter and rib height for which the precision requirement is $\leq 0.20 \mathrm{~mm}$. After communicating with product application manufacturers, the following requirements for sample measurement are put forward:

(1) The inner diameter and rib height must be measured because of the requirement of matching accuracy

(2) There is a need of one station one measurement for the height of the latitudinal ribs, the height of the longitudinal rib, and the inner diameter.

(3) Because of the limitation of production station and production environment, three-dimensional coordinate measuring instrument and other similar professional measuring equipment cannot be used

(4) Because of the requirement of production pace, pure manual measurement is not recommended

In order to meet the requirements of practical application, a three-dimensional robot shape measurement system is adopted, which is composed of industrial robot, indoor global positioning system (iGPS), three-dimensional scanner, and industrial computer. Through the optical threedimensional measurement of the system and the point cloud data processing in the background, the relevant measurement requirements can be completed in one time by means of deviation contrast and satisfy the measurement accuracy, pace, environment, and station.

\subsubsection{Robot Shape Measurement System Construction.}

Based on the indoor global positioning system (iGPS), the three-dimensional robot shape measurement system is shown in Figure 22, which mainly consists of the control computer, the industrial robot, the 3D scanner, the iGPS

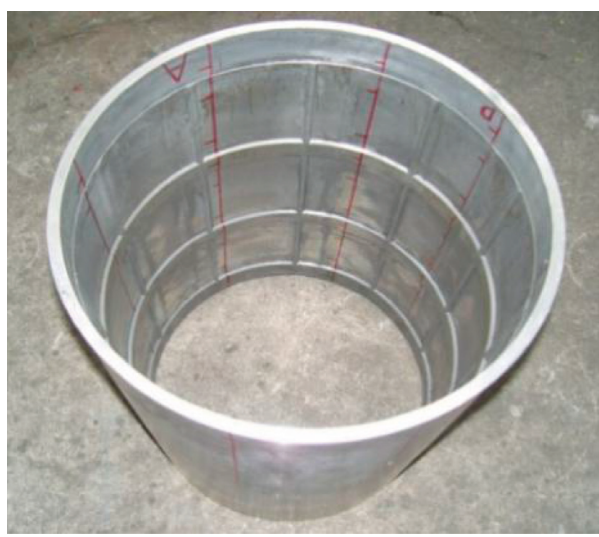

FIgURE 21: Sample of shell with longitudinal and latitudinal inner ribs.

indoor positioning system (iGPS transmitter and iGPS receiver), robot control system, and other components. In the measuring system, the $3 \mathrm{D}$ scanner is rigidly connected to the end flange of the industrial robot through the adapter, and the industrial robot drives the $3 \mathrm{D}$ scanner to perform the station-by-station measurement according to the planned trajectory; the iGPS receiving sensor is installed in the 3D scanner through the fixing seat, receiving the real-time movement through the iGPS positioning and tracking system, and splices the point cloud data of the 3D scanner at each measurement station based on the iGPS world coordinate system. In addition, the entire measurement field is provided with a safety bar and a safety light to ensure the safe movement of the system, as shown in Figure 23.

3.2.2. Measurement. According to the numerical simulation and the process parameters from single-factor test, the samples with rib heights of $2.5 \mathrm{~mm}$ and $4.0 \mathrm{~mm}$ are completed. Due to the length of the paper, only $2.5 \mathrm{~mm}$ sample physical object is presented here as shown in Figure 24. The constructed robotic shape measurement system is used for noncontact measurement, and then the measured point cloud is preprocessed and spliced into a triangular mesh, which is then fitted with the theoretical digital model of the standard sphere and underwent 3D deviation analysis, and the result is shown in Figure 25. This colored 3D deviation distribution bar graph shows that when the point cloud splicing precision is within the range $\pm 0.10 \mathrm{~mm}$, the deviation distribution is relatively uniform, and the splicing effect is better. Table 11 lists the measured dimensions of the samples with rib heights of $2.5 \mathrm{~mm}$ and $4.0 \mathrm{~mm}$, where A, B, $\mathrm{C}$, and $\mathrm{D}$ are equally divided four points in the circumferential direction, and the allowable deviation of the sample is $\pm 0.10 \mathrm{~mm}$. Other measured values are compared with the theoretical value, and the maximum deviation of $0.08 \mathrm{~mm}$ is obtained, which is less than the allowable deviation. And the precision of the spun sample is within the experimental accuracy.

The actual measurement data of the shell parts with $2.5 \mathrm{~mm}$ and $4 \mathrm{~mm}$ height ribs show the capability of the 3D 


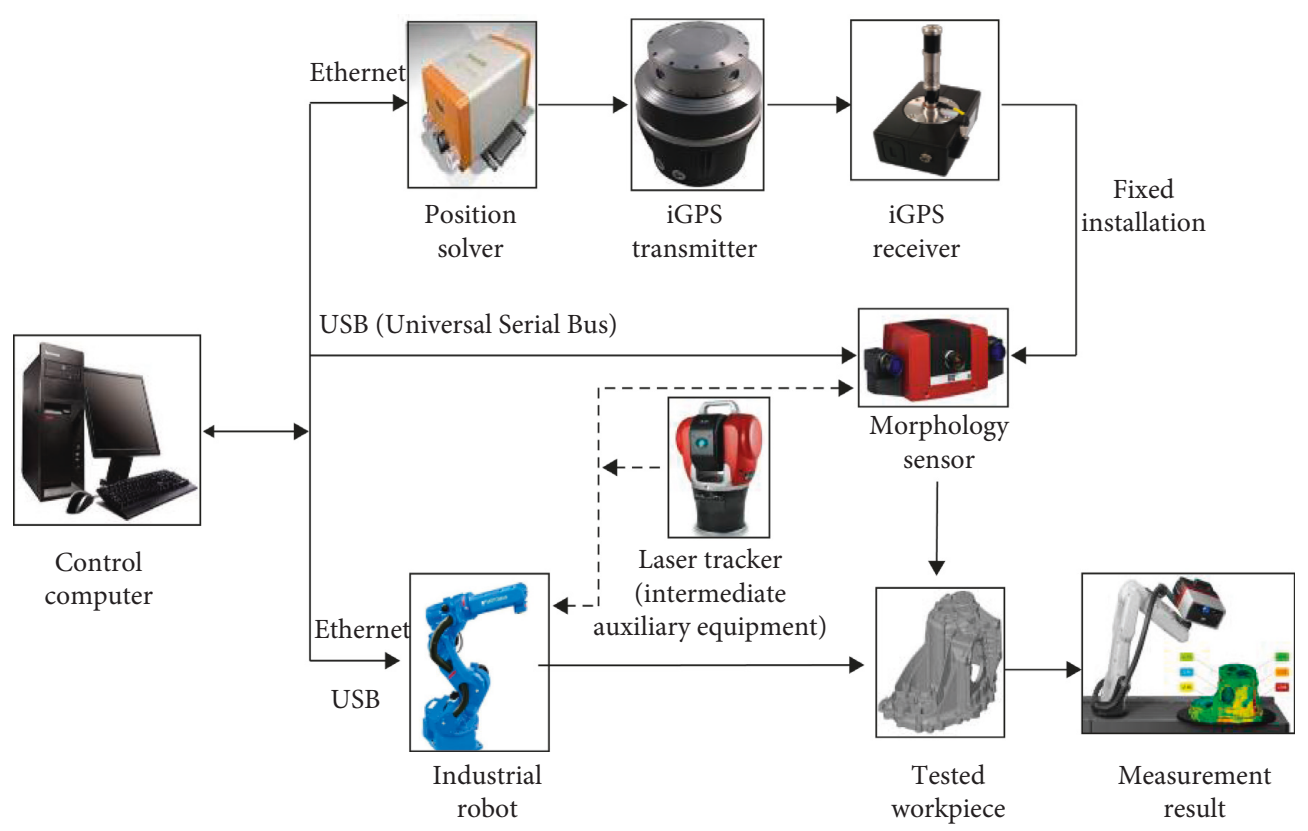

FIgURE 22: System plan composition block diagram.

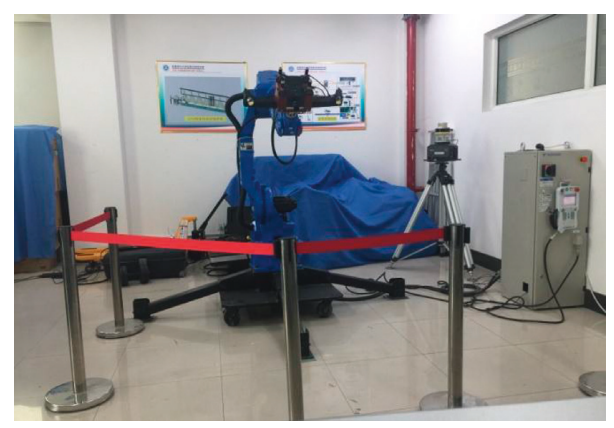

FIGURE 23: 3D shape measurement system based on robot.

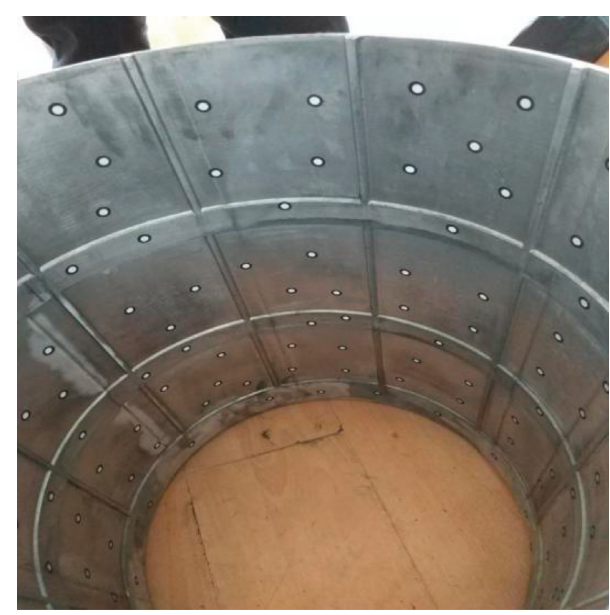

FIgUre 24: Sample with a rib height of $2.5 \mathrm{~mm}$.

robot shape measurement system in the measuring. The optical measurement accuracy is mainly guaranteed by the use of three-dimensional scanning. However, there are some problems related to engineering occasion, such as the needs

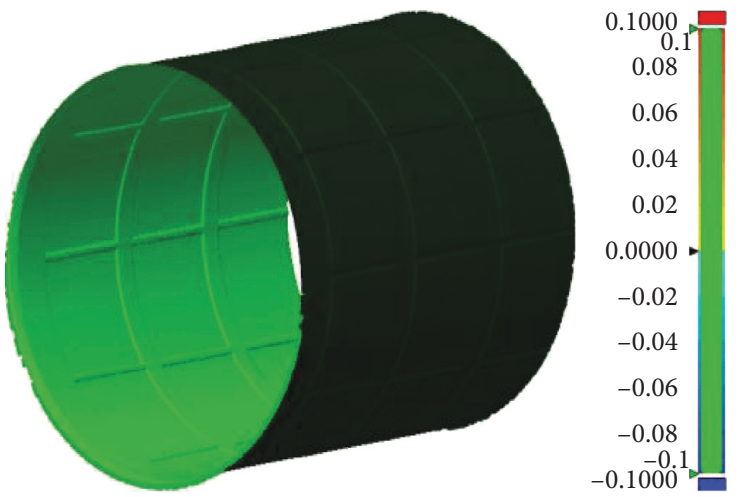

FIGURE 25: 3D deviation analysis of sample with a rib height of $2.5 \mathrm{~mm}$.

of three-dimensional scanner to paste optical dots on the sample at this experiment stage, which cannot meet the requirements of workpiece measurement pace. In addition, it is found that the high-frequency band has a great influence on the IGPS which indicates a fixed station may be needed in real production. 
TABLe 11: Measured dimensions of samples with rib heights of $2.5 \mathrm{~mm} 4.0 \mathrm{~mm}$.

\begin{tabular}{|c|c|c|c|c|c|c|c|c|c|c|c|c|c|c|c|}
\hline & & \multicolumn{7}{|c|}{$\begin{array}{c}\text { Distance from edge to stiffener (stiffener } \\
\text { height of } 2.5 \mathrm{~mm})(\mathrm{mm})\end{array}$} & \multicolumn{7}{|c|}{$\begin{array}{l}\text { Distance from edge to stiffener (stiffener } \\
\text { height of } 4.0 \mathrm{~mm})(\mathrm{mm})\end{array}$} \\
\hline & & 35 & 165 & 210 & 345 & 380 & 510 & 571 & 35 & 165 & 210 & 345 & 380 & 510 & 571 \\
\hline \multirow{5}{*}{$\begin{array}{l}\text { Inside } \\
\text { diameter }\end{array}$} & $\begin{array}{l}\text { Theoretical } \\
\text { value }\end{array}$ & 390.00 & 395.00 & 390.00 & 395.00 & 390.00 & 395.00 & 390.00 & 387.00 & 395.00 & 387.00 & 395.00 & 387.00 & 395.00 & 387.00 \\
\hline & A-C & 390.02 & 395.05 & 390.05 & 395.06 & 390.03 & 395.02 & 390.04 & 387.02 & 395.05 & 387.03 & 395.04 & 387.03 & 395.05 & 387.01 \\
\hline & B-D & 390.01 & 395.02 & 390.03 & 395.08 & 390.02 & 395.05 & 390.02 & 387.04 & 395.07 & 387.04 & 395.06 & 387.02 & 395.03 & 387.04 \\
\hline & $\mathrm{AB}-\mathrm{CD}$ & 390.05 & 395.06 & 390.05 & 395.05 & 390.05 & 395.08 & 390.05 & 387.05 & 395.06 & 387.03 & 395.05 & 387.04 & 395.07 & 387.06 \\
\hline & $\mathrm{AD}-\mathrm{BC}$ & 390.04 & 395.07 & 390.02 & 395.07 & 390.04 & 395.04 & 390.05 & 387.04 & 395.06 & 387.02 & 395.05 & 387.04 & 395.05 & 387.03 \\
\hline \multirow{5}{*}{$\begin{array}{l}\text { Outer } \\
\text { diameter }\end{array}$} & $\begin{array}{l}\text { Theoretical } \\
\text { value }\end{array}$ & 405.00 & 405.00 & 405.00 & 405.00 & 405.00 & 405.00 & 405.00 & 408.00 & 408.00 & 408.00 & 408.00 & 408.00 & 408.00 & 408.00 \\
\hline & A-C & 405.07 & 405.06 & 405.06 & 405.04 & 405.07 & 405.06 & 405.05 & 408.03 & 408.02 & 408.04 & 408.06 & 408.06 & 408.05 & 408.04 \\
\hline & B-D & 405.05 & 405.05 & 405.02 & 405.03 & 405.04 & 405.04 & 405.03 & 408.05 & 408.03 & 408.03 & 408.03 & 408.05 & 408.05 & 408.06 \\
\hline & $\mathrm{AB}-\mathrm{CD}$ & 405.03 & 405.05 & 405.06 & 405.03 & 405.05 & 405.04 & 405.04 & 408.03 & 408.04 & 408.02 & 408.05 & 408.06 & 408.05 & 408.03 \\
\hline & $\mathrm{AD}-\mathrm{BC}$ & 405.03 & 405.03 & 405.02 & 405.03 & 405.01 & 405.02 & 405.01 & 408.06 & 408.05 & 408.03 & 408.02 & 408.05 & 408.03 & 408.05 \\
\hline \multirow{5}{*}{ Thickness } & $\begin{array}{l}\text { Theoretical } \\
\text { value }\end{array}$ & 7.50 & 5.00 & 7.50 & 5.00 & 7.50 & 5.00 & 7.50 & 10.50 & 6.50 & 10.50 & 6.50 & 10.50 & 6.50 & 10.50 \\
\hline & A & 7.54 & 5.02 & 7.53 & 5.03 & 7.52 & 5.02 & 7.54 & 10.51 & 6.53 & 10.52 & 6.52 & 10.52 & 6.53 & 10.52 \\
\hline & B & 7.53 & 5.03 & 7.54 & 5.02 & 7.54 & 5.02 & 7.52 & 10.53 & 6.54 & 10.53 & 6.53 & 10.53 & 6.52 & 10.53 \\
\hline & $\mathrm{C}$ & 7.53 & 5.03 & 7.53 & 5.01 & 7.53 & 5.02 & 7.53 & 10.52 & 6.50 & 10.54 & 6.52 & 10.52 & 6.52 & 10.52 \\
\hline & $\mathrm{D}$ & 7.51 & 5.01 & 7.52 & 5.00 & 7.52 & 5.01 & 7.50 & 10.50 & 6.50 & 10.52 & 6.50 & 10.52 & 6.50 & 10.50 \\
\hline \multirow{5}{*}{ Rib height } & $\begin{array}{l}\text { Theoretical } \\
\text { value }\end{array}$ & 2.50 & & 2.50 & & 2.50 & & 2.50 & 4.00 & & 4.00 & & 4.00 & & 4.00 \\
\hline & A & 2.52 & & 2.50 & & 2.50 & & 2.51 & 4.02 & & 4.02 & & 4.01 & & 4.00 \\
\hline & B & 2.51 & & 2.52 & & 2.52 & & 2.52 & 4.02 & & 4.02 & & 4.01 & & 4.02 \\
\hline & $\mathrm{C}$ & 2.50 & & 2.52 & & 2.51 & & 2.51 & 4.03 & & 4.01 & & 4.02 & & 4.03 \\
\hline & $\mathrm{D}$ & 2.51 & & 2.52 & & 2.51 & & 2.50 & 4.05 & & 4.03 & & 4.03 & & 4.03 \\
\hline
\end{tabular}

\section{Conclusion}

(1) To solve the complicated problem in the spinning process of the longitudinal and latitudinal inner rib shell, the finite element software ABAQUS is used to establish the finite element model, and the orthogonal test method is used to determine the optimization process test parameters according to their influences on the wall thickness difference of the inner rib shell: wall thickness reduction rate $>$ rotary wheel feed speed $>$ rotor working angle. The optimum process data are obtained by analyzing the best combination of the trend group with the minimum wall thickness difference as the optimization target

(2) The spinning test of short workblank is carried out by using the designed split mandrel and the process parameters recommended by simulation. The accuracy of the recommended process parameters is verified by experiments, and the value of the corner radius $R$ of the rotating wheel is corrected according to the experimental results. Finally, the sample with $2.5 \mathrm{~mm}$ rib height is spun by using these parameters. And the sample with $4 \mathrm{~mm}$ rib height was finished by preheating the workblank before spinning.

(3) To achieve the measurement of the shape dimensions of the inner rib shell parts, a 3D robot shape measurement system was developed and built, together with the industrial robot and 3D scanner. The feasibility of the measurement was verified by the measurement data numerical value, but it was also found that the pasting optical punctuation point affected the measurement pace and high-frequency band had a great impact on the indoor positioning system IGPS. Thus, the real application of this measurement system to practical work still needs the necessary optimization and adjustment.

(4) The main innovations of this paper are as follows:

(1) The application of splitting mandrel overcomes the problem of unloading after the spinning forming, and the spinning process of shell parts with longitudinal and latitudinal inner ribs is completed with the support of spinning simulation data.

(2) A three-dimensional robot shape measurement system is developed to meet the demand of actual production and application, through which the size measurement with longitudinal and latitudinal inner ribs is completed. Although there are still some problems in real practice, it proves that the direction of adopting this means is accurate.

\section{Data Availability}

The spinning process parameters of magnesium alloy data used to support the finding of this study are included within the article.

\section{Conflicts of Interest}

The authors declare that there are no conflicts of interest regarding the publication of this paper. 


\section{Acknowledgments}

The research project was funded by the Science and Technology Development Plan of Jilin Province (Project no. 20191004022TC).

\section{References}

[1] Y. Q. Shun, D. Han, Y. T. Yang et al., "Research on precision of spinning forming of large diameter 30CrMnSiA cylinder," China Metal Forming Equipment \& Manufacturing Technology, vol. 6, pp. 89-94, 2018.

[2] P. Y. Xu, H. S. Jia, and W. W. Cheng, "Forming technology of Aluminum alloy cylinder with inner ribbon," Aerial Missile, vol. 3, pp. 81-83, 2015.

[3] Y. H. Dong, B. Zhu, Y. Wang, Y. H. et al., "Nonlinear free vibration of graded graphene reinforced cylindrical shells: effects of spinning motion and axial load," Journal of Sound and Vibration, vol. 437, pp. 79-96, 2018.

[4] X. B. Li, Z. R. Han, T. J. Gao et al., "Finite element simulation of multi-pass spinning forming of large complex thin-wall cylinder," Journal of Shenyang Aerospace University, vol. 33, pp. 32-37, 2016.

[5] J. H. Chen, Q. X. Xia, S. J. Zhang et al., "Application of numerical simulation method in metal spinning," Mechanical and Electrical Engineering Technology, vol. 34, no. 2, pp. 11-14, 2005.

[6] Y. F. Fan, D. N. Li, and W. Z. Chen, "Study on spinning process of AZ31B magnesium alloy sheet," China Mechanical Engineering, vol. 23, no. 11, pp. 1272-1276, 2012.

[7] H. Yang, M. Zhan, T. Li et al., "Advances in spinning of Aluminum alloy large-sized complicated thin walled shells," The Chinese Journal of Nonferrous Metals, vol. 21, no. 10, pp. 2534-2550, 2011.

[8] L. P. Zhang and Z. C. Liu, "Study on the technology of powerful spinning for aluminum alloy cylindrical parts with internal ribbons," Journal of Plastic Engineering, vol. 14, no. 6, pp. 109-113, 2007.

[9] C. Q. Xu, K. M. Xue, and M. Z. Zhou, "Numerical Simulation of rotation forming of ball-shaped tube with inner ribbon," in Proceedings of the Symposium on Electro-Mechanical and Microwave Structural Technology, vol. 8, pp. 265-269, Hohhot, China, 2014.

[10] S. Y. Jiang, K. M. Xue, C. F. Li et al., "Spinning deformation criteria of thin-walled tubular part with longitudinal inner ribs," Journal of Wuhan University of Technology, Materials Science Edition, vol. 21, no. 4, pp. 169-172, 2006.

[11] L. P. Zhang, Z. C. Liu, and H. G. Zhou, "Experimental study on powerful spinning forming of cylindrical parts with inner ribs," Forging Equipment and Manufacturing Technology, vol. 4, pp. 86-88, 2005.

[12] Y. T. Yang, L. W. Zhang, and D. Han, "Strong spinning process database system for cylindrical parts," Heavy Machinery, vol. 1, 2004.

[13] K. M. Xue, S. Y. Jiang, and D. C. Kang, "Strong rotary forming of thin-walled cylindrical parts with longitudinal internal reinforcement," Material Science and Technology, vol. 3, 2002.

[14] K. X. Hua, X. L. Yu, and K. Z. Wang, "Analysis of research status on forming processes and quality control of heavy pressure vessel thick-wall sealing head," Forging and Stamping Technology, vol. 40, no. 2, pp. 8-14, 2015.

[15] T. Zhang, X. H. Li, J. Wei, and S. W. Chang, "Study on the influence of process parameters on spinning quality of thin- walled cylindrical parts with large diameter-thickness ratio," Journal of Plastic Engineering, vol. 24, no. 2, pp. 75-81, 2017.

[16] B. Lin, J. M. Gu, S. R. Zhou et al., "Research on process of multi-pass draw-spinning of hyper-hemispherical shell," Journal of Mechanical Engineering, vol. 47, no. 06, pp. 86-91, 2011.

[17] T. Zhang, Spinning Forming Process, Chemical Industry Press, Beijing, China, 2009.

[18] K. Xu, GH4169 Spinning Simulation Analysis and Experimental Study of Cylindrical Parts with Bottom, Changchun University of Technology, Changchun, Jilin, China, 2018.

[19] H. Tian, Finite Element Simulation and Process Analysis of Cylindrical Spinning, Dalian University of Technology, Dalian, China, 2010.

[20] Z. Cao, Study on Powerful Spinning Process of AZ80 Magnesium Alloy, Shanghai Jiao Tong University, Shanghai, China, 2015.

[21] W. Radtke, "Novel manufacturing methods for titanium tanks and liners," in Proceedings of Joint Propulsion Conference \& Exhibit, pp. 5269-5235, Sacramento, CA, USA, July 2006.

[22] J. Hegels, "Optimized manufacturing methods for large lightweight-overwrapped titanium satellite propellant tanks," in Proceedings of Joint Propulsion Conference \& Exhibit, pp. 4941-4947, Hart ford, CT, USA, July 2008.

[23] H. R. Zhang, M. Zhan, J. Guo et al., "Forming the transverse inner rib of a curved generatrix part through power spinning," Advances in Manufacturing, vol. 7, no. 1, pp. 1-11, 2019.

[24] M. Zhan, J. Guo, F. Chen et al., "Study on external power spinning mechanism of components with transverse inner rib," Journal of Northwestern Polytechnical University, vol. 5, pp. 799-804, 2014.

[25] T. Zhang, Z. C. Liu, and S. C. Ma, "Technologic research and numerical analysis of spinning of cylinders with inner ribs," Chinese Journal of Mechanical Engineering, vol. 43, no. 4, pp. 109-112, 2007.

[26] Q. Bai, H. Yang, and M. Zhan, "Finite element modeling of power spinning of thin-walled shell with hoop inner rib," Transactions of Nonferrous Metals Society of china, vol. 18, no. 1, pp. 6-13, 2008.

[27] F. Ma, H. Yang, Q. Deng, M. Zhan, and L. J. Hu, "Study on the metal flow in power spinning process of parts with transverse inner rib," Advanced Materials Research, vol. 189-193, pp. 2970-2975, 2011.

[28] Z. Wang and S. Ma, "Analysis of thin-walled shells with inner ribs formed by inner spinning technology," Materials Research Innovations, vol. 19, no. 5, pp. S5-101-S5-105, 2016.

[29] M. S. Li, "Philosophy analysis in spinning process," in Proceedings of the 13th Annual Conference of Spinning Technology Exchange, vol. 12, pp. 1-3, Beijing, China, 2013.

[30] C. C. Wong, T. A. Dean, and J. Lin, "A review of spinning shear forming and flow forming processes," International Journal of Machine Tools and Manufacture, vol. 43, no. 2003, pp. 1419-1435, 2003.

[31] J. W. Du, "Metal flow study on extrusion-spinning technology of magnesium alloy cylindrical pieces with circinal inner ribs," North University of China, Taiyuan, China, 2014.

[32] X. Cheng, Z. Lai, and Q. Xia, "Investigation on stress and strain distributions of hollow-part with triangular crosssection by spinning," International Journal of Materials and Product Technology, vol. 47, no. 1/2/3/4, pp. 162-174, 2013. 


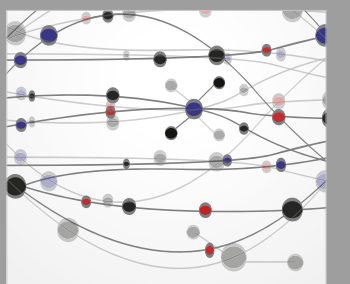

The Scientific World Journal
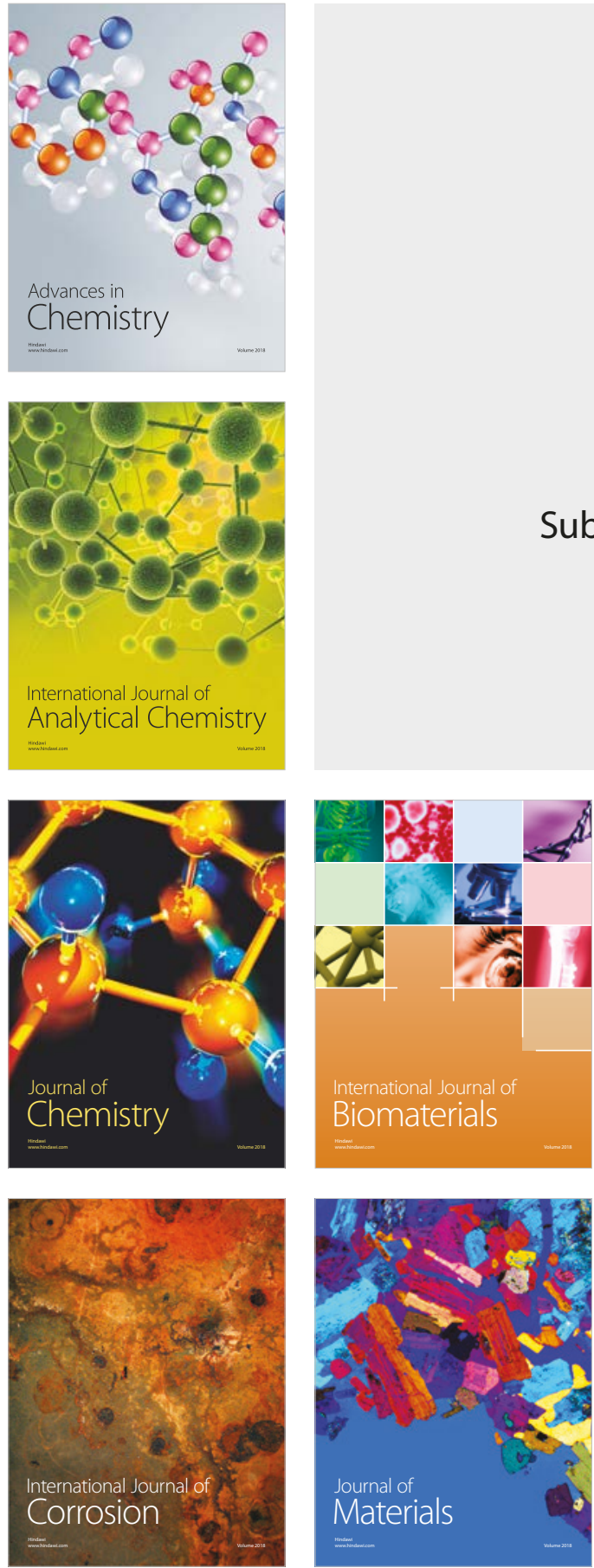

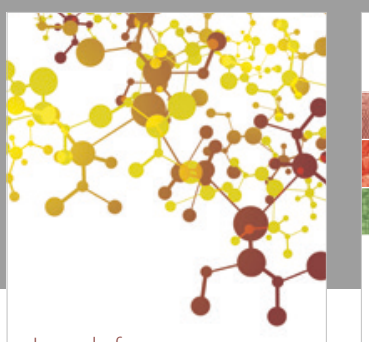

Journal of

Applied Chemistry
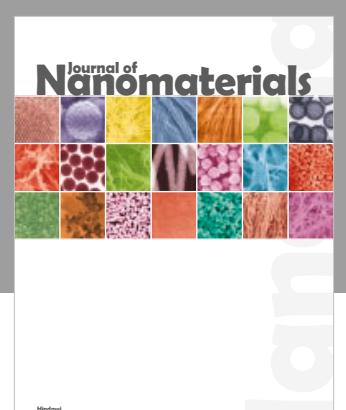

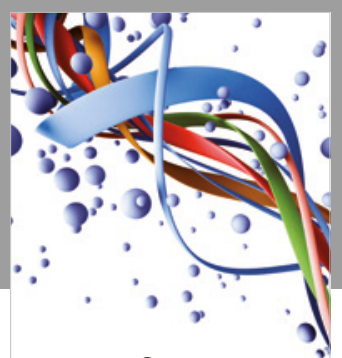

Scientifica

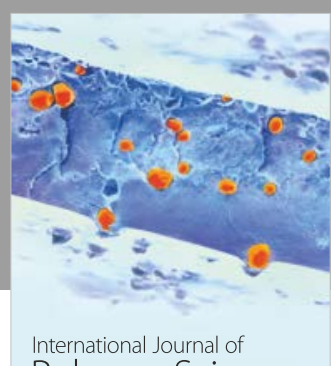

Polymer Science

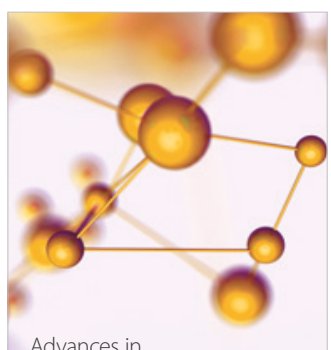

Physical Chemistry
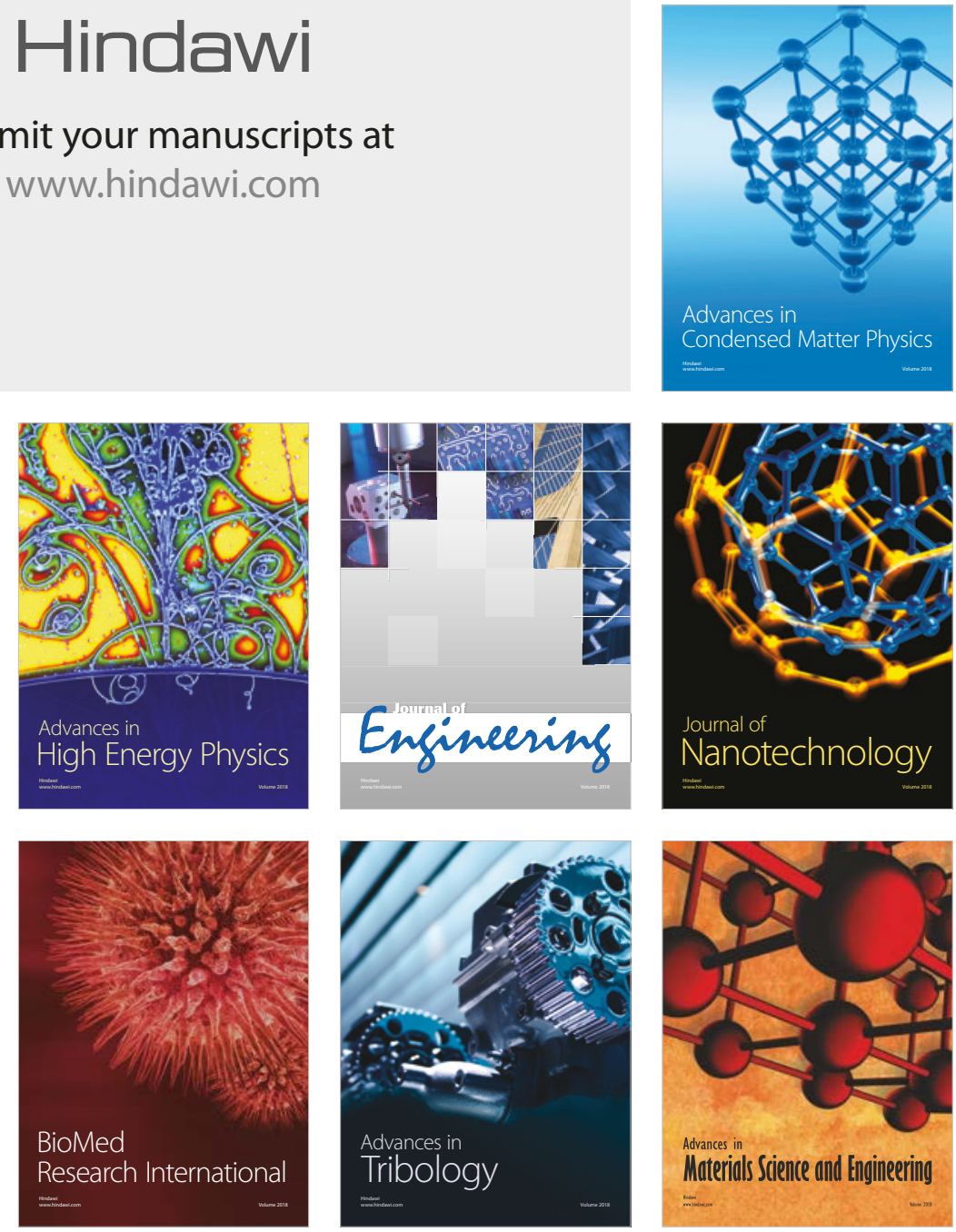